\title{
Semi-automatic spray pyrolysis deposition of thin, transparent, titania films as blocking layers for dye-sensitized and perovskite solar cells
}

\author{
Hana Krýsová ${ }^{1}$, Josef Krýsa ${ }^{* 2}$ and Ladislav Kavan ${ }^{1}$
}

\author{
Full Research Paper \\ Address: \\ 1J. Heyrovský Institute of Physical Chemistry of the CAS, v. v. i., \\ Dolejškova 2155/3, 18223 Prague 8, Czech Republic, and \\ 2University of Chemistry and Technology Prague, Technická 5, 166 \\ 28 Prague 6, Czech Republic \\ Email: \\ Josef Krýsa* - josef.krysa@vscht.cz \\ * Corresponding author \\ Keywords: \\ blocking films; FTO; solar cells; spray pyrolysis deposition; titanium \\ dioxide
}

Beilstein J. Nanotechnol. 2018, 9, 1135-1145. doi:10.3762/bjnano.9.105

Received: 05 October 2017

Accepted: 13 March 2018

Published: 10 April 2018

This article is part of the Thematic Series "Energy conversion, storage and environmental remediation using nanomaterials".

Guest Editor: W.-J. Ong

(C) 2018 Krýsová et al.; licensee Beilstein-Institut. License and terms: see end of document.

\begin{abstract}
For proper function of the negative electrode of dye-sensitized and perovskite solar cells, the deposition of a nonporous blocking film is required on the surface of F-doped $\mathrm{SnO}_{2}$ (FTO) glass substrates. Such a blocking film can minimise undesirable parasitic processes, for example, the back reaction of photoinjected electrons with the oxidized form of the redox mediator or with the holetransporting medium can be avoided. In the present work, thin, transparent, blocking $\mathrm{TiO}_{2}$ films are prepared by semi-automatic spray pyrolysis of precursors consisting of titanium diisopropoxide bis(acetylacetonate) as the main component. The variation in the layer thickness of the sprayed films is achieved by varying the number of spray cycles. The parameters investigated in this work were deposition temperature $\left(150,300\right.$ and $\left.450{ }^{\circ} \mathrm{C}\right)$, number of spray cycles (20-200), precursor composition (with/without deliberately added acetylacetone), concentration $(0.05$ and $0.2 \mathrm{M})$ and subsequent post-calcination at $500{ }^{\circ} \mathrm{C}$. The photo-electrochemical properties were evaluated in aqueous electrolyte solution under UV irradiation. The blocking properties were tested by cyclic voltammetry with a model redox probe with a simple one-electron-transfer reaction. Semi-automatic spraying resulted in the formation of transparent, homogeneous, $\mathrm{TiO}_{2}$ films, and the technique allows for easy upscaling to large electrode areas. The deposition temperature of $450{ }^{\circ} \mathrm{C}$ was necessary for the fabrication of highly photoactive $\mathrm{TiO}_{2}$ films. The blocking properties of the as-deposited $\mathrm{TiO}_{2}$ films (at $450{ }^{\circ} \mathrm{C}$ ) were impaired by post-calcination at $500{ }^{\circ} \mathrm{C}$, but this problem could be addressed by increasing the number of spray cycles. The modification of the precursor by adding acetylacetone resulted in the fabrication of $\mathrm{TiO}_{2}$ films exhibiting perfect blocking properties that were not influenced by post-calcination. These results will surely find use in the fabrication of large-scale dye-sensitized and perovskite solar cells.
\end{abstract}




\section{Introduction}

Dye-sensitized solar cells (DSSCs), solid state dye-sensitized solar cells (SSDSSCs) and perovskite solar cells (PSCs) are attractive alternatives to solid state photovoltaics at competitive cost. The general concept of a DSSC is based on a liquid junction photo-electrochemical cell with a nanocrystalline $\mathrm{TiO}_{2}$ photoanode that is sensitized with a dye. This is in contact with an electrolyte solution with a redox mediator which transports holes from the photo-oxidized dye towards the counter electrode. In SSDSSCs or PSCs, the photogenerated holes are transported by a solid conductive material (e.g., spiro-OMeTAD) $[1,2]$. This is accompanied by the undesirable back reaction of photoinjected electrons with the hole-transporting medium or the oxidized mediator. This reaction occurs both at the $\mathrm{TiO}_{2}$ surface and at the exposed areas of the F-doped $\mathrm{SnO}_{2}$ (FTO) conducting glass that are not covered by the titanium dioxide nanoparticles. In liquid-type DSSCs there is a relatively small recombination current as compared to FTO, which becomes critical in SSDSSCs and perovskite solar cells [3].

For proper function of these solar cells, a semiconducting nonporous blocking layer of oxide (usually $\mathrm{TiO}_{2}$ or $\mathrm{SnO}_{2}$ ) must be deposited on top of FTO to prevent recombination on this surface [3-5]. Blocking layers (BLs) can be fabricated by spray pyrolysis $[3,6]$, magnetron sputtering [7], electrochemical deposition [8] spin coating [9,10], dip coating [11] and atomic layer deposition (ALD) [3].

From the viewpoint of low-cost processing and easy upscaling, spray pyrolysis deposition (SPD) is the most practical option for the fabrication of solar cells. $120-200 \mathrm{~nm}$ thick, compact, $\mathrm{TiO}_{2}$ layers were found to be optimal for SSDSSCs [12]. The same layers (with optimized thickness of 30-35 nm) turned out to be useful for PSCs, where they clearly outperformed the layers made by spin coating [9]. Matteocci et al. [13] used a modified precursor solution which was obtained by addition of acetylacetone to the conventional formulation (i.e., titanium diisopropoxide bis(acetylacetonate)) in ethanol. They fabricated compact $\mathrm{TiO}_{2}$ blocking layers (via SPD) for poly(3-hexylthiophene) SSDSSCs. Their optimised BLs showed an overall increase in the solar cell efficiency, but the blocking function was not quantified, for example, by analysis of the pinhole area [13]. This was one of the motivations for this work.

The blocking properties are often significantly impaired by calcination at $500{ }^{\circ} \mathrm{C}$ (which is mandatory for the subsequent fabrication of mesoporous $\mathrm{TiO}_{2}$ thick films). Even though SPD is a popular technique for the fabrication of BLs and the resulting $\mathrm{TiO}_{2}$ films are less sensitive to calcination, the blocking properties are inferior to those with films prepared by electrodeposition or ALD for example $[3,8]$. Therefore the central moti- vation for this work was SPD fabrication of blocking $\mathrm{TiO}_{2}$ films using conventional [6] and novel [13] spray protocols using a semi-automatic spray device, enabling reproducible and uniform thin transparent titania films to be achieved with good blocking properties and low sensitivity to calcination at the same time. Such fabricated $\mathrm{BL} \mathrm{TiO}_{2}$ films were characterized by photo-electrochemical measurements in aqueous electrolyte solution. The blocking ability was quantified by cyclic voltammetry with a $\mathrm{K}_{3}\left[\mathrm{Fe}(\mathrm{CN})_{6}\right] / \mathrm{K}_{4}\left[\mathrm{Fe}(\mathrm{CN})_{6}\right]$ model redox probe [3].

\section{Experimental}

Two types of FTO glass supports were used with the same nominal sheet resistivity (as declared by the supplier, $8 \Omega / \mathrm{sq}$ ) and thickness $(2.2 \mathrm{~mm})$ : TEC 8 from Libbey-Owens-Ford, labelled as FTO(A) and TEC 8 from Dyesol labelled as FTO(B). Our own measurement of the sheet resistivity showed $12.5 \Omega /$ sq and $7.9 \Omega /$ sq for FTO(A) and FTO(B), respectively. FTO glass slides were cleaned in ethanol and acetone. $\mathrm{TiO}_{2}$ layers were deposited by semi-automatic spray coating set up using two different precursors (i) an ethanolic solution of titanium diisopropoxide bis(acetylacetonate) (abbreviated TAA [6], at concentrations of $0.05 \mathrm{M}$ and $0.2 \mathrm{M}$ ) and (ii) an ethanolic solution of titanium diisopropoxide bis(acetylacetonate) with added acetylacetone with total molar ratio Ti/acetylacetone 1:2.4 (abbreviated TAA-AcAc) [13]. Spraying was carried out by semi-automatic spray device consisting of a nozzle (EST 616, Czech Republic) fed with compressed air (3 bar) and a solution of precursor (flux of $2.7 \mathrm{~cm}^{3} / \mathrm{min}$ ). The nozzle was mounted on a linear stage (velocity $20 \mathrm{~cm} / \mathrm{s}$ ) and the precursor solution was delivered downwards to a heated support $\left(150,300\right.$ or $\left.450{ }^{\circ} \mathrm{C}\right)$. The working area of deposition was up to $20 \times 30 \mathrm{~cm}$, whereby upscaling is technically feasible. During each spray process (lasting approximately $0.5 \mathrm{~s}$ ) a significant decrease of the temperature of the heating plate occurred for several seconds. To avoid this undesired cooling, the next spraying was performed at regular time intervals (30 s) which were necessary for complete layer formation and restoration of the original substrate temperature. This technique allows for the fabrication of films using various numbers of spray cycles (SCs). During the coating procedure, a narrow area at the edge of the FTO glass substrate was protected against deposition of the $\mathrm{TiO}_{2}$ by a mask. This allowed for an ohmic contact to the electrode for subsequent electrochemical and photo-electrochemical tests. Table 1 gives a summary of the fabricated samples. The variable growth parameters were: FTO type (A, B), precursor concentration, deposition temperature, number of spray cycles and influence of the post-calcination step (in air at $500{ }^{\circ} \mathrm{C}$ for $1 \mathrm{~h}$ ).

The produced titania films were characterized by X-ray diffraction (XRD) (PANanalytical X'Pert PRO, Cu K $\alpha$ radiation, 


\begin{tabular}{|c|c|c|c|}
\hline Precursor type and concentration & FTO glass & Substrate temperature $/{ }^{\circ} \mathrm{C}$ & Number of spray cycles \\
\hline \multirow[t]{2}{*}{$0.05 \mathrm{M}$ TAA } & $A$ & 150 & 100 \\
\hline & A & 450 & 100 \\
\hline \multirow[t]{3}{*}{$0.05 \mathrm{M}$ TAA } & $A, B$ & 450 & 50 \\
\hline & $A, B$ & 450 & 100 \\
\hline & $A, B$ & 450 & 200 \\
\hline \multirow[t]{6}{*}{$0.2 \mathrm{M}$ TAA } & B & 450 & 20 \\
\hline & $\mathrm{B}$ & 450 & 30 \\
\hline & $\mathrm{B}$ & 450 & 40 \\
\hline & $\mathrm{B}$ & 450 & 50 \\
\hline & $\mathrm{B}$ & 450 & 60 \\
\hline & $\mathrm{B}$ & 450 & 70 \\
\hline \multirow[t]{6}{*}{$0.2 \mathrm{M}$ TAA- AcAc } & $\mathrm{B}$ & 450 & 20 \\
\hline & $\mathrm{B}$ & 450 & 30 \\
\hline & $\mathrm{B}$ & 450 & 40 \\
\hline & $\mathrm{B}$ & 450 & 50 \\
\hline & B & 450 & 60 \\
\hline & $B$ & 450 & 70 \\
\hline
\end{tabular}

1D XCelerator detector, PANanalytical B.V., Almelo, Netherlands), scanning electron microscopy (SEM) (Hitachi FE SEM S-4800 microscope), and UV-vis spectroscopy (Varian CARY 100 with integrating sphere DRA-CA-30I and $8^{\circ}$ reflectance geometry, Varian, USA). X-ray fluorescence spectroscopy (XRF) analysis was performed on an ARL 9400 XP sequential WD-XRF spectrometer (Thermo ARL, Switzerland) equipped with a Rh anode end window and a 4GN-type X-ray tube fitted with a $50 \mu \mathrm{m}$ Be window. The obtained data were evaluated by Uniquant 4 software.

Photo-electrochemical and electrochemical experiments were carried out in a one-compartment three-electrode cell using an Autolab Pgstat 101 instrument controlled by the NOVA software. The $\mathrm{TiO}_{2}$ thin film on FTO was the working electrode, the reference electrode was $\mathrm{Ag} / \mathrm{AgCl}(3 \mathrm{M} \mathrm{KCl})$ and a platinum rod was used as the counter electrode. The $\mathrm{TiO}_{2}$ films were illuminated from the front side by a $\mathrm{Hg}$ lamp (Oriel), and the $\mathrm{TiO}_{2}$ film area $\left(1 \mathrm{~cm}^{2}\right)$ was defined by a Teflon tape mask. Optical filters were used to select the wavelength range of $320-380 \mathrm{~nm}$. Intermittent light was applied at $10 \mathrm{~s}$ dark/light intervals and the working electrode potential was swept with a scan rate of $5 \mathrm{mV} \mathrm{s}^{-1} .0 .1 \mathrm{M} \mathrm{Na}_{2} \mathrm{SO}_{4}$ ( $\mathrm{pH} \mathrm{10}$ ) was used as the electrolyte solution for photo-electrochemical experiments [14]. The blocking properties of the deposited layers were evaluated by cyclic voltammetry $(\mathrm{CV})$ in aqueous electrolyte solution composed of $0.5 \mathrm{mM} \mathrm{K}_{4}\left[\mathrm{Fe}(\mathrm{CN})_{6}\right], 0.5 \mathrm{mM} \mathrm{K}_{3}\left[\mathrm{Fe}(\mathrm{CN})_{6}\right]$ in $0.5 \mathrm{M} \mathrm{KCl}, \mathrm{pH} 2.5$.

\section{Results and Discussion}

To optimize the SPD conditions, we initially tested the effect of deposition temperature. Our $\mathrm{TiO}_{2}$ films were grown using 100 spray cycles (SCs) using a TAA solution of concentration $0.05 \mathrm{M}$, and the temperature of the FTO substrates was held at 150,300 and $450{ }^{\circ} \mathrm{C}$, respectively. Figure 1a shows the $\mathrm{UV}$-photo-electrochemical scan of a $\mathrm{TiO}_{2}$ film deposited at $150{ }^{\circ} \mathrm{C}$. Without post-calcination at $500{ }^{\circ} \mathrm{C}$, the photocurrent density is negligible. The photoresponse was similarly negligible for the deposition temperature of $300{ }^{\circ} \mathrm{C}$ (data not shown). Only after calcination at $500{ }^{\circ} \mathrm{C}$ will the low-temperature-grown films become photoactive, where the photocurrent onset was observed at around $-0.35 \mathrm{~V}$ (Figure 1a). In the applied potential range of $0.25-1.2 \mathrm{~V}$ there is a photocurrent plateau at $\approx 14 \mu \mathrm{A} / \mathrm{cm}^{2}$ at the UV illumination intensity applied $\left(7.5 \mathrm{~mW} / \mathrm{cm}^{2}\right)$.

For the deposition temperature of $450{ }^{\circ} \mathrm{C}$, our titania films are photoactive already in the as-grown state (see Figure 1b). These $\mathrm{TiO}_{2}$ films exhibit the photocurrent onset at around $-0.3 \mathrm{~V}$ but there is no plateau at larger potentials. Instead, the photocurrent increases monotonically with the applied potential. The effect of post-calcination is opposite compared to the lowtemperature films deposited at $150{ }^{\circ} \mathrm{C}$ (cf. Figure 1a). For instance, at the potential of $1.2 \mathrm{~V}$, we observe a photocurrent density of $\approx 300 \mu \mathrm{A} / \mathrm{cm}^{2}$ for the as-grown film (at $450{ }^{\circ} \mathrm{C}$ ) but only $\approx 240 \mu \mathrm{A} / \mathrm{cm}^{2}$ for the same film, but post-calcined at $500{ }^{\circ} \mathrm{C}$. 

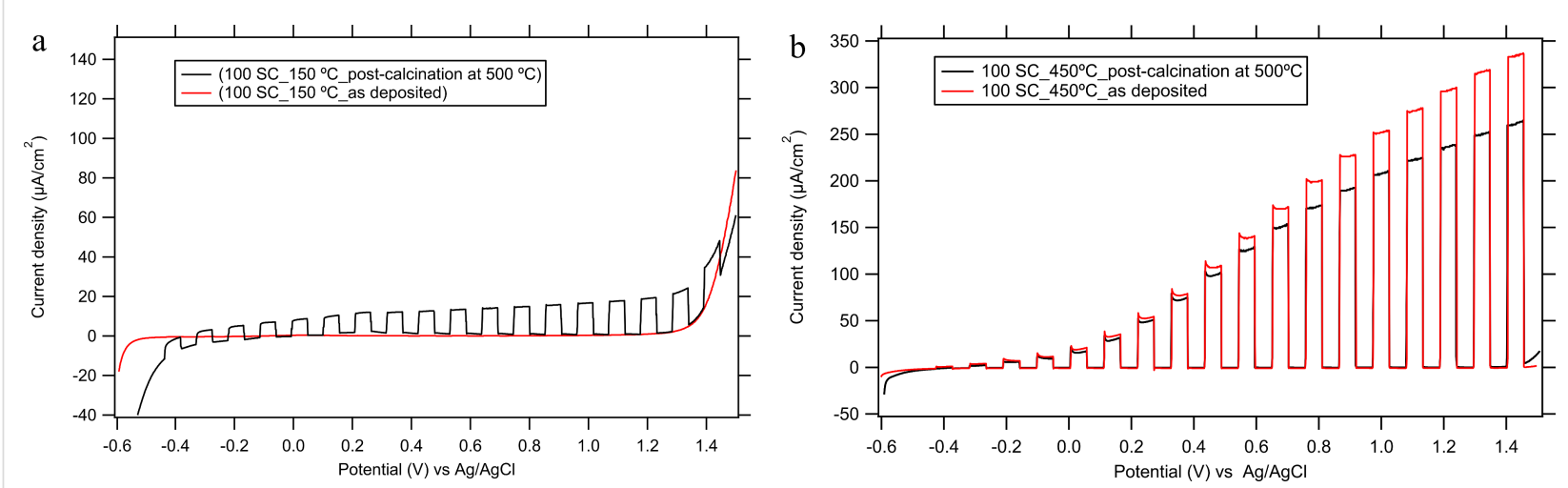

Figure 1: Linear sweep voltammetry under intermittent UV light excitation $(\mathrm{Hg}$ lamp $320-380 \mathrm{~nm})$ of intensity $7.5 \mathrm{~mW} / \mathrm{cm}^{2}$. Comparison of TiO ${ }_{2}$ films (100 SCs) deposited on FTO (A) at $150{ }^{\circ} \mathrm{C}$ (a) and $450{ }^{\circ} \mathrm{C}$ (b) with and without subsequent calcination. The electrolyte solution was $0.1 \mathrm{M} \mathrm{Na}_{2} \mathrm{SO}_{4}$ (pH 10), dark/light intervals of $10 \mathrm{~s}$ were applied.

The onset of anodic dark current for a $\mathrm{TiO}_{2}$ film deposited at $450{ }^{\circ} \mathrm{C}$ occurs at a potential of $\approx 1.45 \mathrm{~V}$. On the other hand the onset potential of the dark anodic current is downshifted to $\approx 1.3 \mathrm{~V}$ for $\mathrm{TiO}_{2}$ films deposited at $150{ }^{\circ} \mathrm{C}$. A similar dark current onset potential (of $\approx 1.3 \mathrm{~V}$ ) was observed on bare FTO under comparable experimental conditions $[15,16]$. This suggests that the $\mathrm{TiO}_{2}$ films deposited at $150{ }^{\circ} \mathrm{C}$ and post-calcined at $500{ }^{\circ} \mathrm{C}$ contain pinholes and cracks through which the electrolyte can reach the FTO surface. As $\mathrm{TiO}_{2}$ is under strong depletion at these potentials, no anodic current of, for example, water oxidation, is expected to flow at the perfectly compact titania electrode in dark.

The blocking quality of our layers was tested in the $\mathrm{pH}$-independent aqueous model redox system $\mathrm{K}_{3}\left[\mathrm{Fe}(\mathrm{CN})_{6}\right] /$ $\mathrm{K}_{4}\left[\mathrm{Fe}(\mathrm{CN})_{6}\right]$ [3]. Nernstian $\mathrm{pH}-$ dependence is demonstrated by the flat-band potential, $\varphi_{\mathrm{FB}}$, of a single-crystal anatase electrode (Equation 1) [17]:

$$
\varphi_{F B}=-0.36-0.059 \mathrm{pH}(\text { in } \mathrm{V} \text { vs } \mathrm{Ag} / \mathrm{AgCl}) \text {. }
$$

As compared to this $\mathrm{TiO}_{2}$ (anatase) flat-band potential, the redox potential of $[\mathrm{Fe}(\mathrm{CN})]_{6}{ }^{3-} /[\mathrm{Fe}(\mathrm{CN})]_{6}{ }^{4-}(0.24 \mathrm{~V}$ vs $\mathrm{Ag} / \mathrm{AgCl})$ is sufficiently positive in aqueous electrolyte solutions at all $\mathrm{pH}$ values. As a result, a rectifying interface, at which no anodic current of $\left[\mathrm{Fe}(\mathrm{CN})_{6}\right]^{4-}$ oxidation flows, is obtained with high-quality titania (anatase) blocking layers because at these potentials titania is in the depletion regime. The cathodic current onset (beginning $\left[\mathrm{Fe}(\mathrm{CN})_{6}\right]^{3-}$ reduction) appears at potentials negative to the $\varphi_{\mathrm{FB}}$ when the titania electrode is in the accumulation regime, mimicking metallic behaviour. Defects, such as cracks in the blocking layer are thus sensitively identified by the occurrence of anodic voltammetric current assigned to the $\left[\mathrm{Fe}(\mathrm{CN})_{6}\right]^{4-}$ oxidation at the exposed FTO areas in pinholes [3].
Figure 2 shows cyclic voltammograms of $\mathrm{Fe}(\mathrm{CN}) 6^{3-/ 4-}$ redox couple at a bare $\mathrm{FTO}(\mathrm{A})$ substrate and that for a sample coated with $\mathrm{TiO}_{2}$ films (100 SCs) of different deposition. Our $\mathrm{TiO}_{2}$ film deposited at $150{ }^{\circ} \mathrm{C}$ without post-calcination displays perfect blocking properties, although it is photo-electrochemically inactive (cf. Figure 1a). Post-calcination of this film causes severe deterioration of its blocking function. The cyclic voltammogram $\mathrm{Fe}(\mathrm{CN})_{6}{ }^{3-/ 4-}$ is similar to that of pure FTO. The

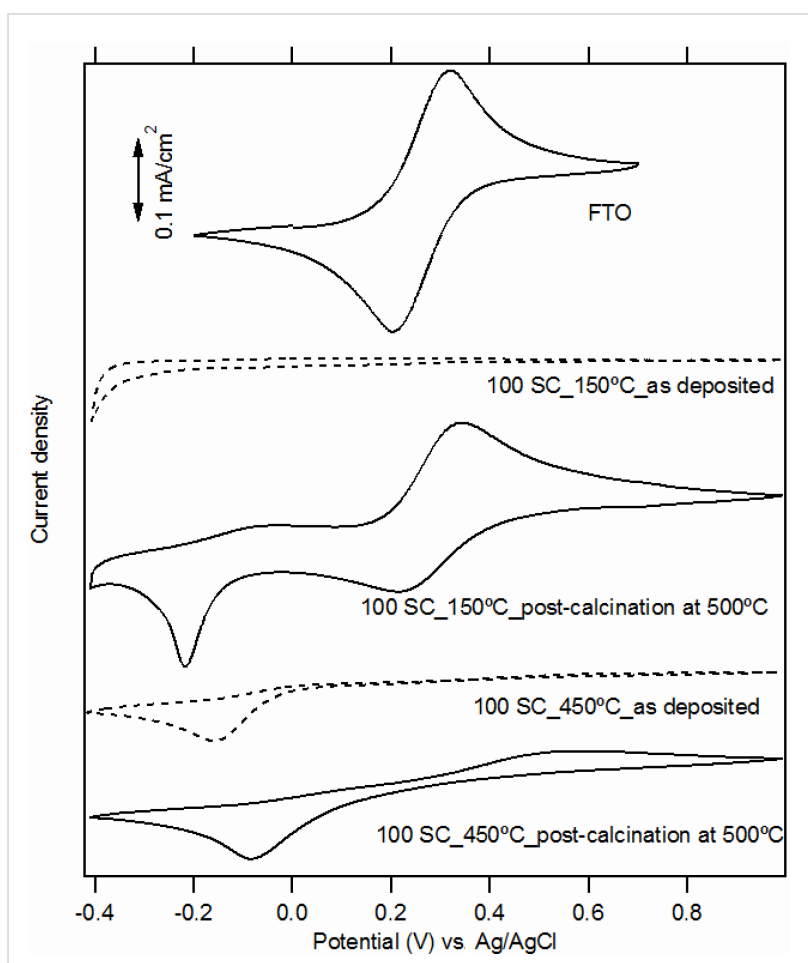

Figure 2: Cyclic voltammograms on an uncoated $\mathrm{FTO}(\mathrm{A})$ electrode and one covered by $\mathrm{TiO}_{2}$ films consisting of $100 \mathrm{SCs}$ of TAA $(0.05 \mathrm{M})$. Scan rate $50 \mathrm{mV} / \mathrm{s}$. Electrolyte solution was $0.5 \mathrm{mM} \mathrm{Fe}(\mathrm{CN})_{6}{ }^{3-14-}$ in aqueous $0.5 \mathrm{M} \mathrm{KCl}, \mathrm{pH} 2.5$. The voltammograms (except for FTO) are offset for clarity but the current density scale is identical for all plots. 
presence of $\mathrm{TiO}_{2}$ manifests itself solely by a cathodic peak at $\approx-0.2 \mathrm{~V}$ which is assigned to the reduction of ferricyanide at the $\mathrm{TiO}_{2}$ surface [3]. On the other hand, the as-grown $\mathrm{TiO}_{2}$ film deposited at $450{ }^{\circ} \mathrm{C}$ has perfect barrier properties, which are less perturbed by the post-calcination.

As a next step, we investigated in detail the influence of layer thickness, which was adjusted by the number of spray cycles (SC, 50-200) of 0.05 M TAA solution. We have chosen the deposition temperature of $450{ }^{\circ} \mathrm{C}$ and have also investigated the influence of the respective FTO glass substrates (A or B, see Experimental section). Figure 3 shows that the photocurrent density increases with the number of SCs for both the FTO substrates.

The onset potential of the dark anodic current ( $\geq 1.4 \mathrm{~V}$ ) suggests a rather compact character of our films deposited at $450{ }^{\circ} \mathrm{C}$. The onset potential of photocurrent is very similar (around $-0.3 \mathrm{~V}$ ) on both our FTO supports and for various layer thicknesses. There is very small slope of the photocurrent/ potential curve around the photocurrent onset and then an almost linear increase of the photocurrent. A similar shape in the polarization curve was observed previously for rutile $\mathrm{TiO}_{2}$ films [18]. However, SPD titania films are likely to be of anatase structure as shown by our XRD analysis (see Figure S1 and
Figure S2 in Supporting Information File 1) and confirmed by others $[3,6,13]$.

Figure 3a,b shows that the type of FTO substrate used significantly influences the photocurrent on the as-deposited $\mathrm{TiO}_{2}$ films. On the FTO(A) substrate, there is a strong increase of photocurrent between 50 and $100 \mathrm{SCs}$ and a less-pronounced increase between 100 and 200 SCs. On the other hand, for FTO(B), the photocurrent increases proportionally with the increase of the number of spray cycles (between 50 and 200 SCs). This FTO-specific behaviour greatly diminishes after post calcination at $500{ }^{\circ} \mathrm{C}$ (Figure $3 \mathrm{c}, \mathrm{d}$ ), which results in a very similar influence of the number of SCs on the photocurrent for both the FTO supports.

Cyclic voltammograms of $\mathrm{Fe}(\mathrm{CN})_{6}{ }^{3-/ 4-}$ redox couple on pure FTO substrates (A or B) are almost identical (cf. Figure 2 for FTO(A)). Figure 4a shows the corresponding cyclic voltammograms on $\mathrm{TiO}_{2}$ films deposited at $450^{\circ}$ on $\mathrm{FTO}(\mathrm{A})$ substrates (50-200 SCs). All $\mathrm{TiO}_{2}$ films have good blocking properties; there is a slight improvement with an increase of the number of SCs, i.e., with the layer thickness. However, after post-calcination, there is a significant deterioration of the blocking properties, and the positive influence of increased SCs on the blocking properties is more apparent (see Figure 4c).
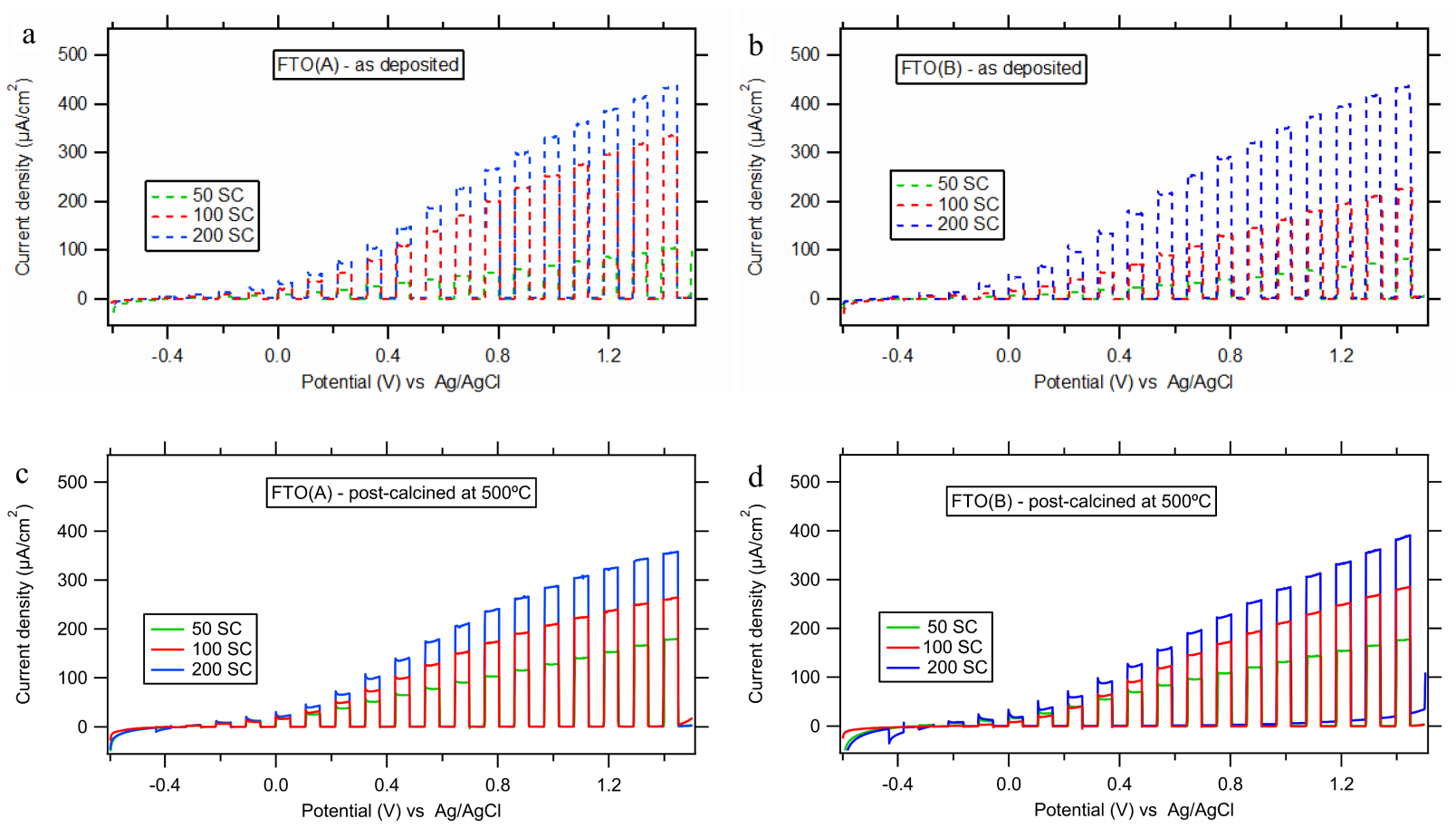

Figure 3: Linear sweep voltammetry under intermittent UV light (Hg lamp 320-380 nm; intensity $\left.7.5 \mathrm{~mW} / \mathrm{cm}^{2}\right)$. Precursor: $0.05 \mathrm{M}$ TAA, deposition temperature: $450{ }^{\circ} \mathrm{C}$, electrolyte solution: $0.1 \mathrm{M} \mathrm{Na}_{2} \mathrm{SO}_{4}(\mathrm{pH} \mathrm{10}$ ), dark/light interval: $10 \mathrm{~s}$. (a,c) Films deposited on FTO(A) 50,100 and $200 \mathrm{SCs}$. (b,d) Films deposited on FTO(B) 50, 100 and 200 SCs. 

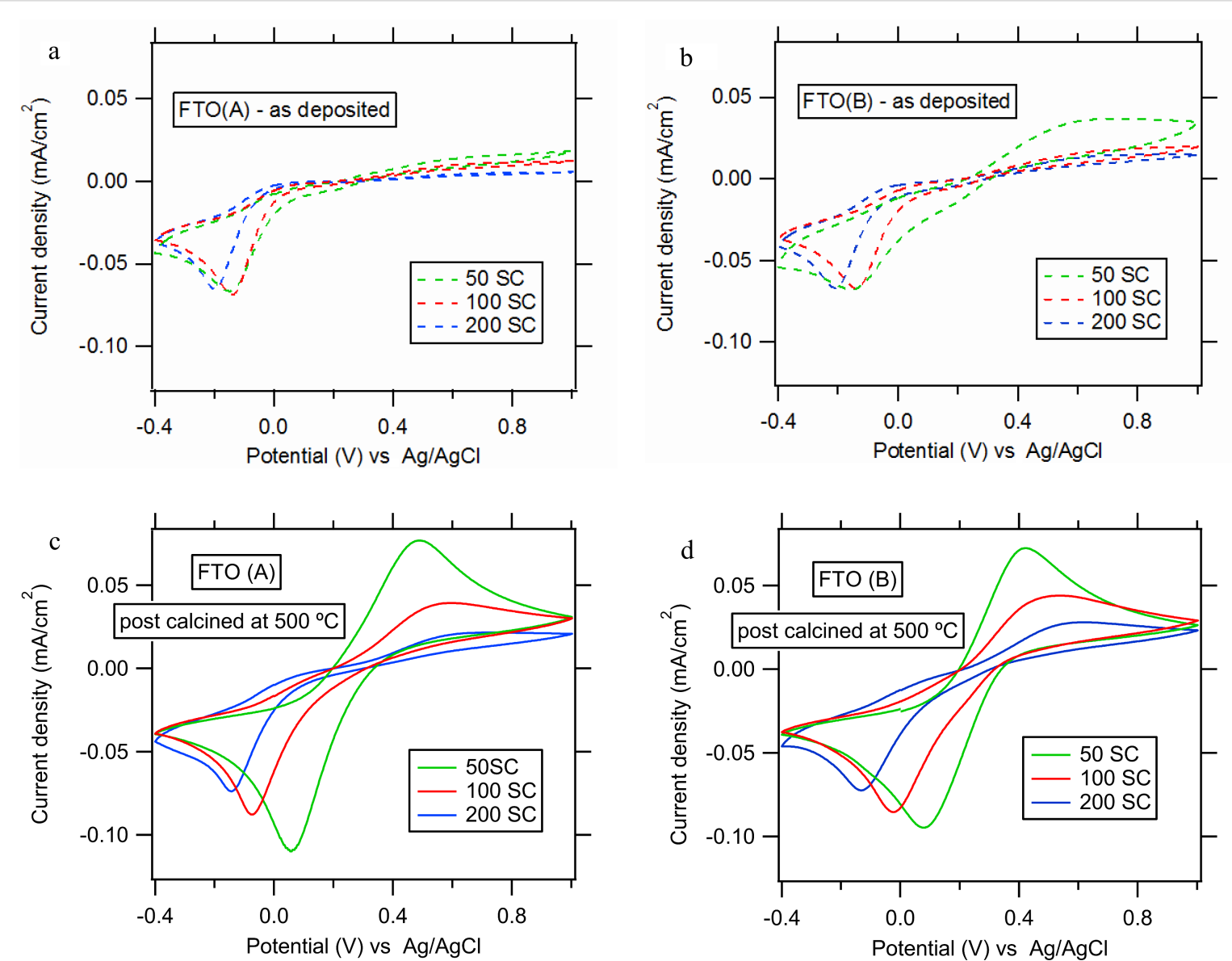

Figure 4: Cyclic voltammograms for $\mathrm{TiO}_{2}$ films; precursor: $0.05 \mathrm{M} \mathrm{TAA}$, deposition temperature: $450{ }^{\circ} \mathrm{C}$, scan rate: $50 \mathrm{mV} / \mathrm{s}$, electrolyte solution: $0.5 \mathrm{mM} \mathrm{Fe}(\mathrm{CN})_{6}{ }^{3-/ 4-}$ in aqueous $0.5 \mathrm{M} \mathrm{KCl}, \mathrm{pH}$ 2.5. (a,c) films deposited on FTO(A) 50,100 and $200 \mathrm{SCs}$, (b,d) films deposited on FTO(B) 50 , 100 and 200 SCs.

A similar behaviour was observed for the $\mathrm{TiO}_{2}$ films deposited on the FTO(B) substrate, but the blocking properties were not as good as than those for $\mathrm{TiO}_{2}$ films deposited on FTO(A), especially for the lowest thickness (50 SCs), see Figure 4b. Also, the post calcination at $500{ }^{\circ} \mathrm{C}$ results in a significant deterioration of the blocking properties, see Figure $4 \mathrm{~d}$.

Although the used substrates (FTO(A) and FTO(B)) are nominally identical (TEC 8; differing solely by the supplier, see Experimental section) we observed a surprisingly strong influence of the substrate type on the blocking properties of titania films which were sprayed over them. More specifically, FTO(A) provides considerably better blocking properties of the corresponding titania films. To address this peculiarity, we investigated these substrates in more detail and the results are summarized below.

Figure 5 shows the top surface morphology of both our FTO substrates. The grain size is between 100 and $200 \mathrm{~nm}$ for FTO(A), but between 300 and $500 \mathrm{~nm}$ for FTO(B). Further- more, $\mathrm{FTO}(\mathrm{B})$ is less transparent than $\mathrm{FTO}(\mathrm{A})$, whereby the optical transmittance in the range of wavelengths from 350 to $550 \mathrm{~nm}$ is by about $15-20 \%$ lower, which is consistent with the difference in the structure. The coherent domain size calculated from X-ray line broadening by the Scherrer equation was $24 \mathrm{~nm}$ for FTO(A) and $36 \mathrm{~nm}$ for FTO(B). These values are consistent with the difference in the grain size for both the FTO samples. Our own measurement of sheet resistivity provided the following values. FTO(A), TEC8, Libbey-Owens-Ford: $12.5 \Omega /$ sq and FTO (B), TEC 8, Dyesol: $7.9 \Omega /$ sq. This finding is quite surprising and implies that $\mathrm{FTO}(\mathrm{B})$ has a higher resistivity (by about $50 \%$ ) than that declared by the supplier.

The larger grain size of the FTO(B) substrate is the apparent reason for its incomplete coverage by titania film. Figure $4 \mathrm{a}$ illustrates this finding, which is particularly expressed for the smallest thicknesses (50 SCs). For a larger number of SCs (100 and 200) the differences between our FTO substrates are damped. The evaluation of the fraction coverage of FTO by the titania blocking layer is based on the voltammetric current den- 
(a) FTO(A) - TEC 8, Libbey-Owens-Ford

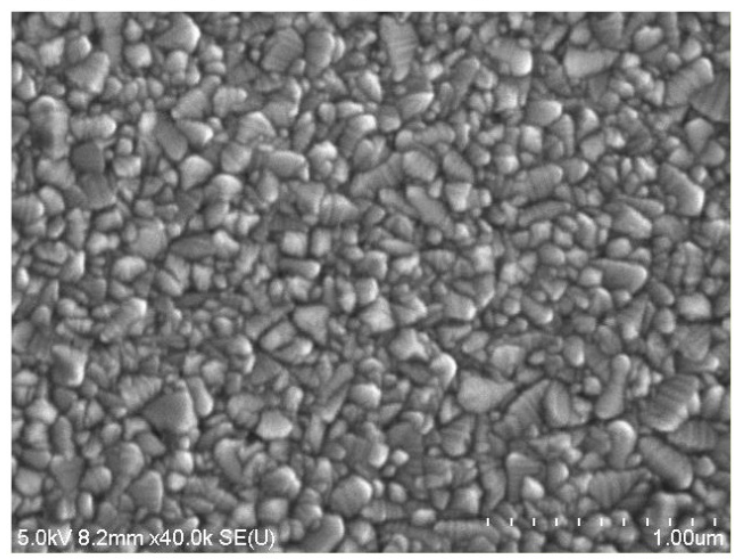

(b) FTO(B) - TEC8, Dyesol

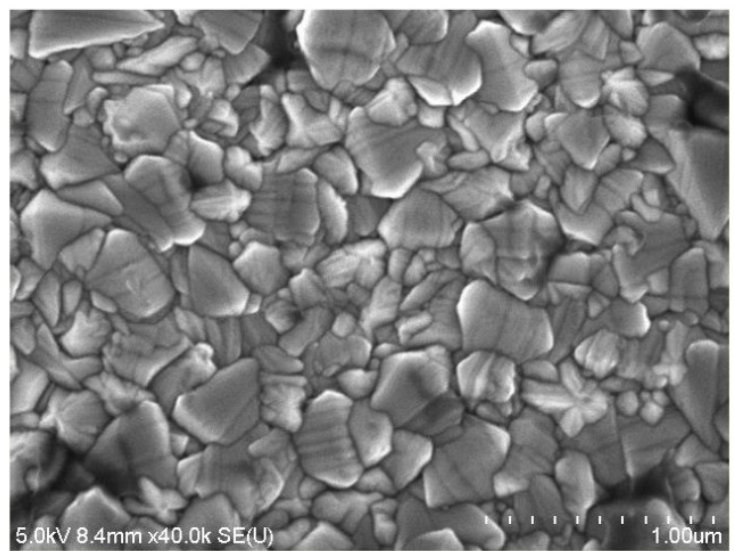

Figure 5: Top view SEM images of FTO glass substrates, (a) FTO(A) and (b) FTO(B).

sity peak, $j_{\mathrm{p}}$, which follows the Randless-Sevcik equation [3]. The effective pinhole area (EPA) can be expressed by Equation 2 as

$$
\mathrm{EPA}=\frac{A_{\mathrm{u}}}{A_{0}}=\frac{j_{\mathrm{p}}}{j_{\mathrm{p}, \mathrm{FTO}}}(\%)
$$

where $j_{\mathrm{p}}$ is the peak current density (with reference to the projected electrode area, $A_{0}$ ) measured at the actual blocking electrode, $A_{\mathrm{u}}$ is the uncovered area of FTO and $j_{\mathrm{p}, \mathrm{FTO}}$ is the current density peak measured at a bare FTO electrode. The actual values are listed in Table 2. As suggested in a previous work [3], there are two types of defects in the barrier film: (i) "defect A" - the partially blocked electrode behaves like a "clean" FTO but with a relatively smaller effective area. The relative increase of voltammetric peaks separation $\left(\Delta E_{\mathrm{pp}}\right)$ on the $\mathrm{BL}$ normalized to that for pure FTO is smaller than 3. ( $\Delta E_{\mathrm{pp}}$ is defined as the difference between the peak potentials for the $\mathrm{Fe}(\mathrm{CN})_{6}{ }^{4-}$ oxidation and $\mathrm{Fe}(\mathrm{CN})_{6}{ }^{3-}$ reduction). (ii) "defect $\mathrm{B}$ " - a more complex situation, where the defect causes not only the delamination of the titania film from FTO, but also the slowdown of charge transfer kinetics (accompanied by a strong increase in $\left.\Delta E_{\mathrm{pp}}\right)$.

The barrier properties after post calcination were fairly good for the $0.05 \mathrm{M}$ TAA precursor and the largest layer thickness ( 200 SCs), but still $\approx 10-13 \%$ of the FTO surface was uncovered by $\mathrm{TiO}_{2}$ (Table 2). Therefore, in the next step, the concentration of TAA was increased to $0.2 \mathrm{M}$ to achieve a larger film thickness per one spray cycle. FTO(B) was chosen as a substrate due to the conformity of its measured/declared sheet resistivity and also as a solution for the reduced blocking performance of thin $\mathrm{TiO}_{2}$ films deposited on it (cf. Figure 4a,c and

\begin{tabular}{|c|c|c|c|c|c|c|c|}
\hline \multirow[t]{2}{*}{ Substrate } & \multirow[t]{2}{*}{ Precursor } & \multirow[t]{2}{*}{ No. of SCs } & \multicolumn{2}{|c|}{$j_{\mathrm{p}}\left(\mathrm{mA} \mathrm{cm}{ }^{-2}\right)$} & \multicolumn{2}{|c|}{ EPA (\%) } & \multirow[t]{2}{*}{ Defect type } \\
\hline & & & as dep. & calcined & as dep. & calcined & \\
\hline $\mathrm{FTO}(\mathrm{A})$ & - & - & 0.15 & - & 100 & - & - \\
\hline $\mathrm{FTO}(\mathrm{A})$ & 0.05 TAA & 50 & 0.020 & 0.075 & 13 & 50 & A \\
\hline $\mathrm{FTO}(\mathrm{A})$ & 0.05 TAA & 100 & 0.013 & 0.035 & 9 & 23 & $A+B$ \\
\hline $\mathrm{FTO}(\mathrm{A})$ & 0.05 TAA & 200 & 0.006 & 0.02 & 4 & 13 & B \\
\hline $\mathrm{FTO}(\mathrm{B})$ & 0.05 TAA & 50 & 0.040 & 0.07 & 27 & 47 & A \\
\hline $\mathrm{FTO}(\mathrm{B})$ & 0.05 TAA & 100 & 0.017 & 0.03 & 11 & 20 & $A+B$ \\
\hline FTO(B) & 0.05 TAA & 200 & 0.010 & 0.015 & 7 & 10 & B \\
\hline $\mathrm{FTO}(\mathrm{B})$ & 0.2 TAA & 20 & 0.010 & 0.02 & 7 & 13 & B \\
\hline FTO(B) & 0.2 TAA & 50 & 0.005 & 0.01 & 3 & 7 & B \\
\hline FTO(B) & $0.2 \mathrm{TAA}$ & 70 & 0.002 & 0.005 & 1 & 3 & B \\
\hline $\mathrm{FTO}(\mathrm{B})$ & 0.2 TAA-AcAc & 70 & 0.002 & 0.002 & 1 & 1 & B \\
\hline
\end{tabular}


Figure $4 b, d)$. The actual $\mathrm{TiO}_{2}$ films were deposited by 20 to 70 spray cycles at $450{ }^{\circ} \mathrm{C}$ and again the influence of the postcalcination was investigated. The photocurrent response was measured similarly as in Figure 3. For the as-deposited films as well as the calcined films, the photocurrent density slightly increases with increasing number of SCs (from 20 to 40), but remains constant for higher SCs (between 50 and 70). The observed photocurrent density at a potential of $1.2 \mathrm{~V}$ was $460 \mu \mathrm{A} / \mathrm{cm}^{2}$ for the calcined $\mathrm{TiO}_{2}$ film from $0.2 \mathrm{M}$ TAA (50 SCs). Figure $3 \mathrm{~b}$ and Figure $3 \mathrm{~d}$ illustrate that this photocurrent is roughly comparable to that on the calcined thick film from diluted solution (0.05 M-TAA; $200 \mathrm{SCs})$, i.e., $350 \mu \mathrm{A} / \mathrm{cm}^{2}$.

Figure S3 in Supporting Information File 1 shows the cyclic voltammograms of FTO(B) covered by $\mathrm{TiO}_{2}$ films deposited by $20 \mathrm{SCs}$ of $0.2 \mathrm{M}$ TAA. There is a large improvement of the blocking properties when compared to the previous set of samples (Figure 4b,d). More detailed CV data are shown in Figure 6 for the $\mathrm{TiO}_{2}$ films consisting of 20,50 and $70 \mathrm{SCs}$. In all cases, post-calcination causes a strong deterioration of the blocking properties. The difference between as-deposited $\mathrm{TiO}_{2}$ films and those after post-calcination is a dampening with increasing number of SCs. For instance, at $70 \mathrm{SCs}$, the difference is almost negligible.

Figure 7 shows the top surface morphology of our FTO(B) and that of the substrate covered by $\mathrm{TiO}_{2}$ films consisting of various SCs. A thin $\mathrm{TiO}_{2}$ film (20 SCs) is barely visible on top of FTO (Figure $7 \mathrm{~b}$ ), where the image is dominated by the substrate morphology. With increasing number of SCs, the grains of FTO become covered by small $\mathrm{TiO}_{2}$ particles, which provide the blocking function of the electrode (Figure 7c). Interestingly, post-calcination does not result in any significant increase of the $\mathrm{TiO}_{2}$ particle size, as seen in Figure 7d.
From the comparison of Figure 6 and Figure 4b,d it follows that the as-deposited and post-calcined $\mathrm{TiO}_{2}$ films consisting of 20 SCs (0.2 TAA) have comparable blocking properties to the $\mathrm{TiO}_{2}$ film consisting of $200 \mathrm{SCs}$ (0.05 TAA). With increasing number of SCs (from 20 to 70), the negative influence of postcalcination on the blocking properties of $\mathrm{TiO}_{2}$ films further diminishes (cf. Figure 6 and the EPA values in Table 2).

In the last step, we investigated the influence of the precursor solution composition. Figure 8 compares the cyclic voltammograms of $\mathrm{Fe}(\mathrm{CN})_{6}{ }^{3-/ 4-}$ on $\mathrm{FTO}(\mathrm{B})$ covered by $\mathrm{TiO}_{2}$ films consisting of $70 \mathrm{SCs}$ by two precursors, $0.2 \mathrm{M}$ TAA and $0.2 \mathrm{M}$ TAA-AcAc, where the latter was enriched with added acetylacetone (see Experimental section). Although the 70 SC TAA film has already quite good blocking properties even after postcalcination, examination of the details in the curves shows that the TAA-AcAc films are still better. The shift of the electroreduction peak, or in some cases the missing electroreduction (at $-0.2 \mathrm{~V}$ ), is a sign of good coverage of the electroactive FTO by the $\mathrm{TiO}_{2}$ film, which has properties comparable to those of a perfect anatase single crystal. The latter has a flat band potential $\left(\varphi_{\mathrm{FB}}\right)$ (cf. Equation 1$)$ at $\approx-0.5 \mathrm{~V}$ at the given experimental conditions (as in Figure 8). Hence, no electroreduction of ferricyanide to ferrocyanide is expected to occur at $-0.2 \mathrm{~V}$, because anatase is in the depletion regime. This is indeed observed for our TAA-AcAc films. Actually, the occurrence of the electroreduction peak at $-0.2 \mathrm{~V}$ at some other compact (pinhole-free) $\mathrm{TiO}_{2}$ layers (cf. Figure 6) is less clear from this point of view. A tentative interpretation could consider the fact that certain $\mathrm{TiO}_{2}$ films (e.g., those grown by ALD) do show their $\varphi_{\mathrm{FB}}$ significantly upshifted (by $\approx 0.3 \mathrm{~V}$ ), see e.g. [3].

Our conclusion concerning a significant difference in the properties of the BL resulting from the two compositions of spray pyrolysis precursors is a bit empirical, and the comparison of
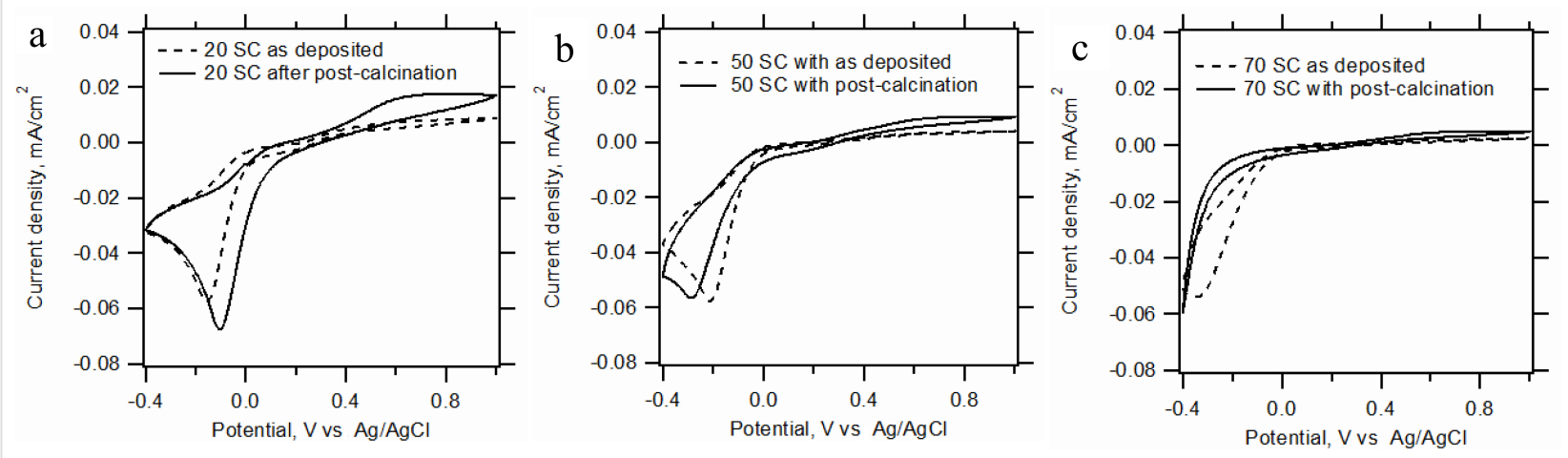

Figure 6: Cyclic voltammograms on a $\mathrm{FTO}(\mathrm{B})$ substrate covered by $\mathrm{TiO}_{2}$ films of (a) $20 \mathrm{SCs}$, (b) $50 \mathrm{SCs}$ and (c) $70 \mathrm{SCs}$ of $0.2 \mathrm{M}$ TAA. Scan rate $50 \mathrm{mV} / \mathrm{s}$. Electrolyte solution was $0.5 \mathrm{mM} \mathrm{Fe}(\mathrm{CN})_{6}{ }^{3-/ 4-}$ in aqueous $0.5 \mathrm{M} \mathrm{KCl}, \mathrm{pH} 2.5$. 
(a)

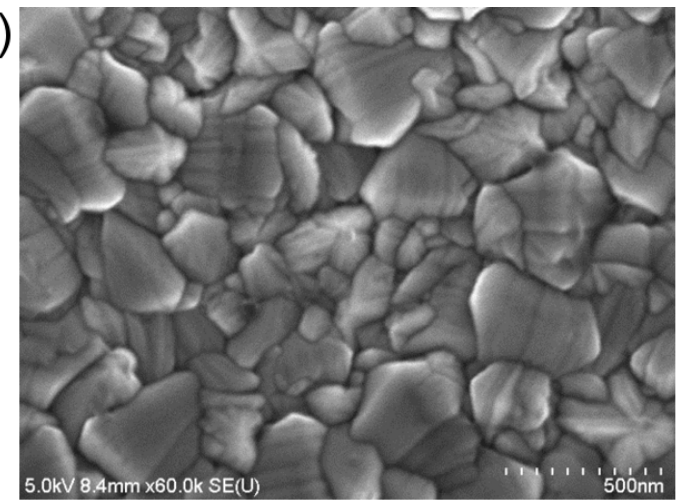

(c)

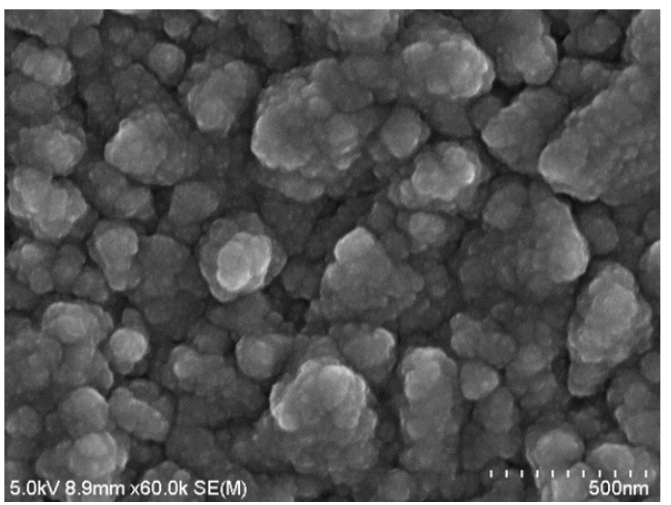

(b)

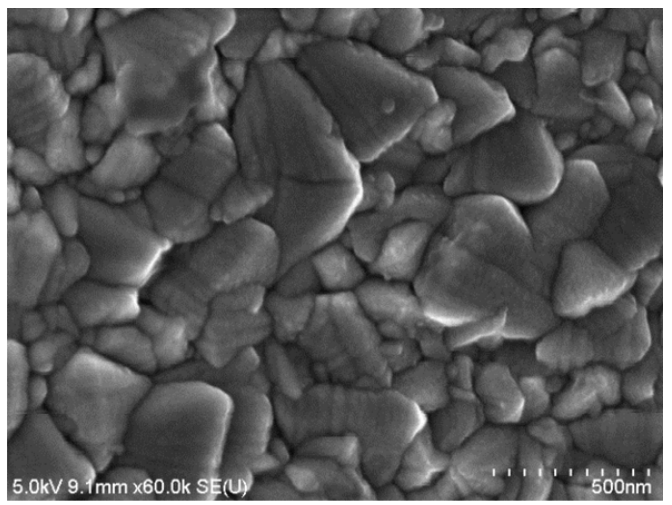

(d)

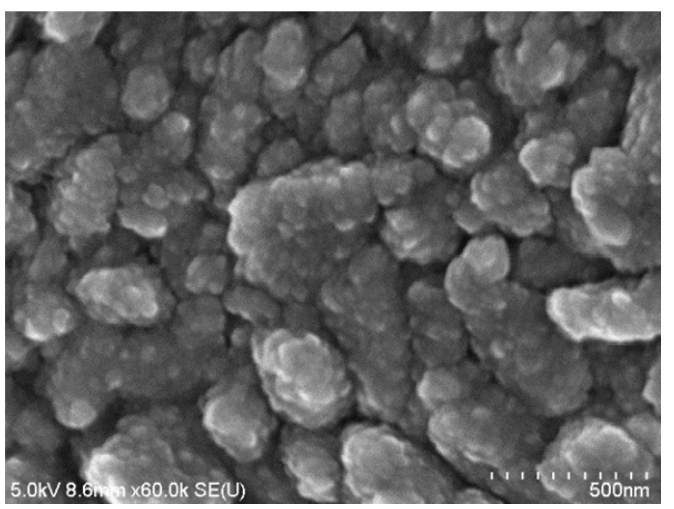

Figure 7: Top view SEM images of a) bare FTO(B), b) FTO(B) covered by 20 SCs of $0.2 \mathrm{M} \mathrm{TAA}, \mathrm{c}$ ) FTO(B) covered by 70 SCs of $0.2 \mathrm{M}$ TAA and d) FTO(B) covered by $70 \mathrm{SCs}$ of $0.2 \mathrm{M} \mathrm{TAA}$ with post-calcination at $500^{\circ} \mathrm{C}$.

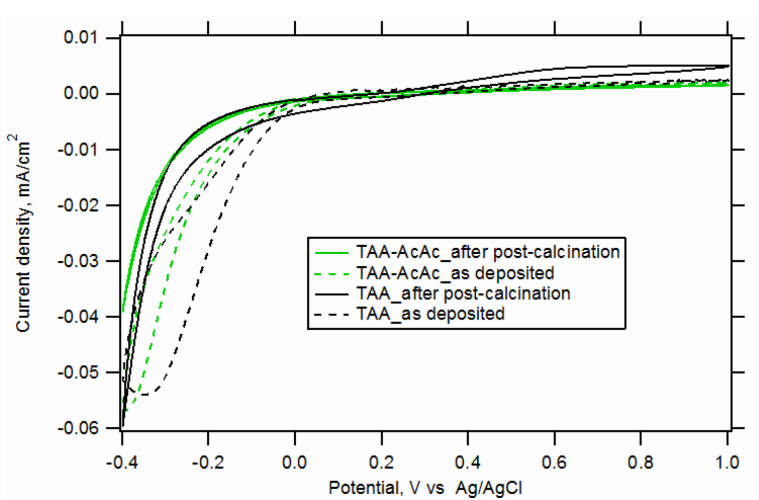

Figure 8: Cyclic voltammograms of $\mathrm{FTO}(\mathrm{B})$ covered by sprayed $\mathrm{TiO}_{2}$ films made of $70 \mathrm{SCs}$ of $0.2 \mathrm{M} \mathrm{TAA}$ and of $0.2 \mathrm{M}$ TAA-AcAc. Scan rate $50 \mathrm{mV} / \mathrm{s}$. Electrolyte solution was $0.5 \mathrm{mM} \mathrm{Fe}(\mathrm{CN})_{6}{ }^{3-/ 4-}$ in aqueous $0.5 \mathrm{M} \mathrm{KCl}, \mathrm{pH} 2.5$.

TAA vs TAA-AcAc is not reinforced by deeper discussion of the growth mechanism and structure of the products. Matteocci et al. [13] assumed that acetylacetone can induce functionalization of FTO, aiding in turn an efficient anchoring of $\mathrm{TiO}_{2}$ to FTO. This hypothesis is rationalized by the well-known chelating effect of acetylacetone on both organometallic com- plexes and on oxidic surfaces. The optimization through compositional variation is limited by the growth of complicated species, particularly if the acetylacetone concentration is too high [13]. In a closely related study, Boland et al. [19] used IR spectroscopy to confirm that the precursor solution made by mixing of titanium (IV) isopropoxide with acetylacetone contains an excess of unchelated acetylacetone for the Ti/AcAc ratio $\geq 3$. Hence, we (in accord with the cited works and references therein) assume that our used precursor solution has the optimal composition already.

From the XRD analysis, an anatase crystalline structure was not detected for any as-deposited $\mathrm{TiO}_{2}$ films even those consisting of 70 SCs (0.2 M TAA), see Figure S1 in Supporting Information File 1. For post-calcined $\mathrm{TiO}_{2}$ films, anatase can be detected only for films consisting of 70 SCs (only one band $\left(\theta=25.4^{\circ}\right)$, see Figure $\mathrm{S} 1$ in Supporting Information File 1. Similarly, XRD analysis of the 70 SC TAA-AcAc film shows that the anatase band $\left(\theta=25.4^{\circ}\right)$ is visible only after post-calcination.

Surface XRF analysis of the $\mathrm{TiO}_{2}$ film consisting of $50 \mathrm{SCs}$ (0.2 M TAA) shows the content of Ti equal to $8.1 \mu \mathrm{g} / \mathrm{cm}^{2}$. 
Assuming that the film contains only $\mathrm{TiO}_{2}$ we obtain the mass of our $\mathrm{TiO}_{2}$ to be $13.3 \mu \mathrm{g} / \mathrm{cm}^{2}$ and the corresponding thickness of the $\mathrm{TiO}_{2}$ film (using the density of $3.8 \mathrm{mg} / \mathrm{cm}^{3}$ ) equal to $36 \mathrm{~nm}$. Analogously, the thicknesses of our $\mathrm{TiO}_{2}$ films consisting of 20,50 and $70 \mathrm{SCs}(0.2 \mathrm{M}$ TAA) are 14,36 and $50 \mathrm{~nm}$, respectively. This rather low layer thickness together with the very small size of the sprayed $\mathrm{TiO}_{2}$ particles (see Figure $7 \mathrm{c}, \mathrm{d}$ ) is responsible for the very weak XRD response.

We should note that our layer thicknesses are considerably smaller than those reported previously for dye-sensitised solar cells (the thicknesses were typically 100-200 nm) [6,13], and are in the thickness region which was optimized previously for perovskite solar cells $(30-35 \mathrm{~nm})[9,11]$. However, the cited work used solely the stoichiometric titanium diisopropoxide bis(acetylacetonate) without any added acetylacetone. Our results support the earlier finding by Matteocci et al. [13], that the addition of extra acetylacetone for BL fabrication is beneficial for the efficiency of poly(3-hexylthiopene) solar cells. Here we extended this finding by an analysis of the blocking function of these layers. To the best of our knowledge, this analysis as well as the systematic screening of deposition conditions is carried out in this work for the first time.

\section{Conclusion}

Transparent $\mathrm{TiO}_{2}$ films were prepared by spray pyrolysis using precursors consisting of an ethanolic solution of titanium diisopropoxide bis(acetylacetonate) (TAA) with or without additional acetylacetone added. The films were deposited on FTO glass substrates at temperatures of 150,300 and $450{ }^{\circ} \mathrm{C}$ using a semiautomatic spray device, enabling control of the film homogeneity and thickness over a large area. The minimal deposition temperature of $450{ }^{\circ} \mathrm{C}$ was identified for obtaining the photo-electrochemically active, as-grown films. An increase in the precursor concentration affords the corresponding increase of layer thickness normalized to the number of the deposition cycles. The need of careful selection of an FTO substrate is highlighted by a comparison of two nominally identical products from two suppliers. The as-deposited $\mathrm{TiO}_{2}$ films (at $450{ }^{\circ} \mathrm{C}$ ) of thickness $\approx 15 \mathrm{~nm}$ prepared from precursor TAA exhibit good blocking properties with an effective pinhole area (EPA) smaller than $10 \%$. However, post-calcination of the as-grown films at $500{ }^{\circ} \mathrm{C}$ had a negative influence on the blocking properties. The problem could be addressed by increasing the number of spray cycles (thickness $\approx 50 \mathrm{~nm}$ ) so that an EPA of $\approx 3 \%$ is achieved. The negative influence of the postcalcination is further minimized by deliberate addition of acetylacetone to the precursor solution. In this way, high-quality barrier films were fabricated (EPA $\approx 1 \%$ ) which do not suffer from any loss in blocking function after subsequent post-calcination. To the best of our knowledge, the unperturbed blocking utility of our calcined films is shown here for the first time. Furthermore, good blocking is observed for calcined films, which are similar or thinner than those reported earlier by spray pyrolysis deposition. This finding is significant for the fabrication of DSSCs, SSDSSCs and perovskite solar cells.

\section{Supporting Information}

\section{Supporting Information File 1}

Additional experimental data.

[https://www.beilstein-journals.org/bjnano/content/

supplementary/2190-4286-9-105-S1.pdf]

\section{Acknowledgements}

This work was supported by the Grant Agency of the Czech Republic (contracts No. 17-20008S and 18-08959S). This work was also supported by the Ministry of Education, Youth and Sports of the Czech Republic and The European Union - European Structural and Investments Funds in the frame of Operational Programme Research Development and Education - project Pro-NanoEnviCz (Reg. No. CZ.02.1.01/0.0/0.0/16_013/ 0001821). The authors would like to thank to Martin Zlamal (UCT Prague) for the set-up of the spray pyrolysis device.

\section{ORCID ${ }^{\circledR} \mathrm{iDs}$}

Ladislav Kavan - https://orcid.org/0000-0003-3342-4603

\section{References}

1. Hagfeldt, A.; Boschloo, G.; Sun, L.; Kloo, L.; Pettersson, H. Chem. Rev. 2010, 110, 6595-6663. doi:10.1021/cr900356p

2. Kavan, L. Curr. Opin. Electrochem. 2017, 2, 88-96. doi:10.1016/j.coelec.2017.03.008

3. Kavan, L.; Tétreault, N.; Moehl, T.; Grätzel, M. J. Phys. Chem. C 2014, 118, 16408-16418. doi:10.1021/jp4103614

4. Cameron, P. J.; Peter, L. M. J. Phys. Chem. B 2003, 107, 14394-14400. doi:10.1021/jp030790+

5. Cameron, P. J.; Peter, L. M. J. Phys. Chem. B 2005, 109, 930-936. doi:10.1021/jp0405759

6. Kavan, L.; Grätzel, M. Electrochim. Acta 1995, 40, 643-652. doi:10.1016/0013-4686(95)90400-W

7. Braga, A.; Baratto, C.; Colombi, P.; Bontempi, E.; Salvinelli, G.; Drera, G.; Sangaletti, L. Phys. Chem. Chem. Phys. 2013, 15, 16812-16818. doi:10.1039/c3cp52250d

8. Kavan, L.; O'Regan, B.; Kay, A.; Grätzel, M. J. Electroanal. Chem. 1993, 346, 291. doi:10.1016/0022-0728(93)85020-H

9. Wang, P.; Shao, Z.; Ulfa, M.; Pauporté, T. J. Phys. Chem. C 2017, 121, 9131-9141. doi:10.1021/acs.jpcc.7b00979

10. Jeong, I.; Park, Y. H.; Bae, S.; Park, M.; Jeong, H.; Lee, P.; Ko, M. J. ACS Appl. Mater. Interfaces 2017, 9, 36865-36874. doi:10.1021/acsami.7b11901

11. Masood, M. T.; Weinberger, C.; Sarfraz, J.; Rosqvist, E.; Sandén, S.; Sandberg, O. J.; Vivo, P.; Hashmi, G.; Lund, P. D.; Österbacka, R.; Smått, J.-H. ACS Appl. Mater. Interfaces 2017, 9, 17906-17913. doi:10.1021/acsami.7b02868 
12. Peng, B.; Jungmann, G.; Jäger, C.; Haarer, D.; Schmidt, H.-W.; Thelakkat, M. Coord. Chem. Rev. 2004, 248, 1479-1489. doi:10.1016/j.ccr.2004.02.008

13. Matteocci, F.; Mincuzzi, G.; Giordano, F.; Capasso, A.; Artuso, E.; Barolo, C.; Viscardi, G.; Brown, T. M.; Reale, A.; Di Carlo, A. Org. Electron. 2013, 14, 1882-1890. doi:10.1016/j.orgel.2013.03.037

14. Krysa, J.; Lee, K.; Pausova, S.; Kment, S.; Hubicka, Z.; Ctvrtlik, R.; Schmuki, P. Chem. Eng. J. 2017, 308, 745-753. doi:10.1016/j.cej.2016.09.112

15. Waldner, G.; Krýsa, J.; Jirkovský, J.; Grabner, G. Int. J. Photoenergy 2003, 5, 115-122. doi:10.1155/S1110662X03000229

16. Krýsa, J.; Baudys, M.; Zlámal, M.; Krýsová, H.; Morozová, M.; Klusoň, P. Catal. Today 2014, 230, 2-7. doi:10.1016/j.cattod.2014.01.008

17. Kavan, L.; Grätzel, M.; Gilbert, S. E.; Klemenz, C.; Scheel, H. J. J. Am. Chem. Soc. 1996, 118, 6716-6723. doi:10.1021/ja954172।

18. Waldner, G.; Krýsa, J. Electrochim. Acta 2005, 50, 4498-4504. doi:10.1016/j.electacta.2005.02.028

19. Boland, S. W.; Pillai, S. C.; Yang, W.-D.; Haile, S. M. J. Mater. Res. 2004, 19, 1492-1498. doi:10.1557/JMR.2004.0199

\section{License and Terms}

This is an Open Access article under the terms of the Creative Commons Attribution License (http://creativecommons.org/licenses/by/4.0), which permits unrestricted use, distribution, and reproduction in any medium, provided the original work is properly cited.

The license is subject to the Beilstein Journal of

Nanotechnology terms and conditions:

(https://www.beilstein-journals.org/bjnano)

The definitive version of this article is the electronic one which can be found at:

doi:10.3762/bjnano.9.105 